This is the pre-print version of:

Shin, W. (2017). Active mediation of television, internet, and mobile advertising. Young Consumers, 18(4), 378-392.

\title{
ACTIVE MEDIATION OF TELEVISION, INTERNET, AND MOBILE ADVERTISING
}

\begin{abstract}
Purpose: The purposes of this study are (1) to examine how parents implement discussion-based parental mediation (i.e., active mediation) to influence the way children understand advertising on television, computers, and smartphones, and (2) to investigate factors associated with parental mediation practices.
\end{abstract}

Design/methodology/approach: A survey was conducted with parents in Singapore whose children were watching television, using computers with internet access, and using smartphones. Findings: The degree to which parents engage in active mediation of advertising is similar across different media. Active mediation of advertising is more a function of parents' attitudes toward advertising directed to children, parents' concerns about media influence on their children, and parental self-efficacy, rather than the age of their children.

Research limitations/implications: The survey was conducted in a single country and did not examine the consequences of parental mediation of advertising. Future research should consider cross-cultural perspectives and investigate the outcomes of parental mediation.

Practical implications: For advertising practitioners, this study argues that it is important to understand how parents view different forms of advertising. For media educators and policy makers, this study suggests that various parental factors should be considered to develop effective guidelines for parents. 
Originality/value: This study adds novel insights to the literature on consumer socialization by investigating how parents - the primary socialization agents in children's development of consumption-related behaviors - help children understand advertising across different media.

Keywords: Advertising, children, parental mediation, consumer socialization, Singapore, screen media.

Paper type: Research paper 
Children have access to numerous forms of screen media including television, computers, and smartphones (Common Sense Media, 2015), and they spend substantial time engaging in multiple media activities (Wakefield, 2015). As they do so, children are exposed to a wider range of advertising messages, including TV commercials, online advertising, and mobile marketing (Federal Trade Commission, 2013; Wilcox et al., 2004). That exposure may enhance children's understanding of marketplace and advertising tactics (Austin and Reed, 1999; Schor, 2004). However, it can also create important "unintended effects" (Buijzen and Valkenberg, 2003, p. 484) such as parent-child conflict, materialism, and unhealthy food consumption (Buijzen, 2009; Dens et al., 2007). Research suggests that young consumers are more vulnerable to the unintended effects of advertising than are their adult counterparts, due to weaknesses in the cognitive skills needed to understand advertising intentions (Wilcox et al., 2004). Some of the current forms of advertising targeted to children, including product placement in online or mobile games, brand websites, brand logos and promotional messages displayed on youthoriented websites, often blur the line between advertising messages and non-commercial content, making children even more vulnerable to the persuasive intention of advertisers (Moore, 2006; Neeley, 2007; Wilcox et al., 2004).

Parents serve as socialization agents who can influence how children understand and process media messages (Buijzen, 2009; Laczniak and Carlson, 2012; Neeley, 2007). However, today's media environment poses unique challenges for parents in several ways. First, many children watch television in their bedrooms and use computers and mobile devices outside of the home (Common Sense Media, 2013). Second, children often hide their online and mobile behavior from their parents by clearing the browser history or deleting instant messages 
(McAfee, 2012). Third, children tend to view their media use as a personal activity, and thus, often resist parental oversight (Valkenburg et al., 2013).

Under these circumstances, media monitoring and control may not constitute viable options for parents wishing to manage their children's media usage. An alternative solution would be to engage in communication-based media intervention (Shin, 2015). Research suggests that communication-based parental mediation, also known as active mediation, is more effective than control-based media interventions in influencing children's attitudes and behaviors regarding media, even for tech-savvy children in the new media environment (Shin and Kang, 2016; Youn, 2008). However, most research on parental mediation has focused on media-related mediation, i.e. how parents mediate children's media use in general. As a result, the body of literature on active mediation more specifically related to advertising, i.e. how parents talk about advertising, is relatively small. Even the few studies focusing on active mediation of advertising are typically limited to analysis of a single advertising medium (Buijzen, 2009; Vanwesnbeeck et al., 2016). Given that children today are multitaskers, using multiple media platforms concurrently and being exposed to a wide range of advertising strategies and tactics through both traditional and new media, it is important to understand how parents engage in active mediation to modify the effects of advertising on their children across different media.

The goal of this study is to examine how parents implement active mediation to influence the way children understand advertising on television, computers, and smartphones, and to investigate the factors associated with parental mediation practices. Specifically, this study explores (1) how parents talk to their children about advertising that appears on television, computers, and smartphones, and (2) how factors associated with both children and parents (such as a child's age, parents' concern about their child's use of media, parents' attitude toward 
advertising to children, and parental self-efficacy) account for differences in what parents do to mitigate the negative influence of advertising on children. Findings from this study will help generate a better understanding of the role that parents play in children's acquisition of persuasion knowledge (Friestad and Wright, 1994) through multi-media, as well as the factors that account for it.

\section{Active Mediation}

Parental mediation refers to the intervention strategies that parents employ to supervise and guide children's media usage in order to maximize the positive impacts of media while minimizing its negative influence (Warren, 2001). The three general approaches to mediating children's media use include active mediation (i.e. parents explaining and discussing media content with their children), restrictive mediation (i.e. parents limiting children's access to media), and co-using (i.e. parent-child shared media experiences without involving media-related discussions) (Shin and Kang, 2016; Warren, 2001). Prior studies have found that active mediation tends to be more effective than other types of parental mediation in reducing undesirable media influences on both young and older children (Lwin et al., 2008; Youn, 2008). Fujioka and Austin (2003) suggest that this is the case because mediation based on conversation and critical discussion between parents and children is more likely to cultivate critical thinking skills and skepticism in children than are other mediation types. Active mediation also provides opportunities for children to further inquire about parents' comments, thereby deepening their understanding of parental expectations (Shin, 2015).

While most of the research on parental mediation has examined media-related parental intervention (e.g. how parents guide and supervise children's television viewing in general), one line of parental mediation research has focused specifically on parental mediation of one type of 
communication - advertising. This line of research also identifies active mediation as a key mediation strategy for parents (Buijzen and Valkenburg, 2003). In this line of research, active mediation refers to parents making deliberate comments and judgments about advertising and explaining the nature and intent of advertising to their children (Buijzen, 2009). In keeping with findings from the broader media-related literature, (e.g. Lwin et al., 2008; Shin and Kang, 2016; Youn, 2008), research on parental mediation of advertising has also revealed that active mediation is more effective than other forms of mediation in enhancing children's understanding of advertising (Bijmolt et al., 1998) as well as in reducing the negative influences of advertising on children, such as advertising-induced materialistic attitudes and purchase requests (Buijzen and Valkenburg, 2005) and unhealthy food consumption (Buijzen, 2009). However, the existing research on parental mediation of advertising has focused primarily on children's exposure to TV commercials. Research on parental mediation of new media advertising is scant, despite the fact that children today spend increasing amounts of time on multiple screen media and expose themselves to a variety types of advertising (Kowalczyk and Royne, 2016). To address this shortcoming in parental mediation research and to understand the nature of active mediation of advertising, this study asks two research questions:

RQ1: To what extent is active mediation practiced by parents to influence their children's understanding of advertising on television, computers (with Internet access) and smartphones?

RQ2: Do parents engaging in higher levels of active mediation of advertising also engage in higher levels of active mediation of media use more generally? 


\section{Antecedents of Active Mediation}

One of the consistent findings in parental mediation research is that the age of children is negatively associated with the level of parental mediation in both traditional (Hoffner and Buchanan, 2002; Nathanson, 2001) and new media contexts (Livingstone et al., 2011; Shin and Lwin, 2017). Shin and Lwin (2017) argue that this negative relationship can be explained by the diminishing role of parents as socialization agents for older children. Specifically, as children grow older, they tend to spend more time with external socialization agents such as peers and school teachers and less time with parents, making parental interventions less influential (John, 1999). Older children also tend to be more competent media users and consumers as compared to younger children, spending substantial time on a wide range of media and having an enhanced understanding of the marketplace (John 1999; Moore \& Lutz, 2000; Openhaffen et al., 2012). Parents of older children, thus, may believe that their children have sufficient familiarity with various media platforms and marketing practices. Therefore, it is predicted that parents of older children should be less likely than parents of younger children to practice active mediation of advertising:

H1: The age of children will be negatively associated with active mediation of advertising.

Regarding parental perceptions of media effects, researchers have found that parents who are concerned about negative media influences on their own children are more likely to implement higher levels of parental mediation. Warren (2001) shows that parents with greater concern about the negative effects of child-inappropriate television content on their children are more likely to practice a higher level of active mediation. Similarly, Nathanson (2001) finds that the degree to which parents think violent television will have harmful effects on their children is 
positively associated with levels of active mediation of children's television viewing. Outside the television context, Nikken and Jansz (2006) demonstrate that parents who believe that video games have a negative influence on their children's behaviors and attitudes are more likely to engage in active mediation. Following existing research, this study poses a second hypothesis:

H2: Parents' concerns about their child's use of each type of media (television, computers, and smartphones) will be positively associated with their active mediation of advertising through each medium.

While in a broader sense it may be obvious that the extent to which parents are concerned about the influence of media on their children would influence their approach to parental mediation, less is known regarding how parents' attitudes toward specific forms of communication, such as advertising, might affect their parental mediation strategies. Only a few studies have examined the role of parents' attitudes toward advertising in parental mediation behavior, despite the fact that attitude is one of the key determinants of behavior generally (Fishbein and Ajzen, 2011). Austin and her colleagues find that the degree to which parents make negative comments about television content to their children is positively correlated with skepticism toward advertising (Austin and Pinkleton, 2001) and negatively associated with trust in advertising (Austin et al., 1999). One study (Kowalczyk and Royne, 2016) specifically examined mothers' attitudes toward advertising to children as a potential antecedent of parental restrictive mediation of children's media use and found a positive association between parents' negative attitude toward advertising to children (e.g. "advertising teaches children bad habits") and parental restrictive mediation of children's television viewing and video game playing. However, to the best of my knowledge, none of the existing studies have examined parents' attitudes toward advertising targeted to children as a potential determinant of active mediation of 
advertising across different media. Given that parents tend to have negative attitudes toward advertising targeted to children in general (Dens et al., 2007; Kowalczyk and Royne, 2016) and that one's attitude can lead to specific behaviors (Fishbein and Ajzen, 2011), it is important to examine whether parents' negative attitudes toward advertising to children influence their "talk" on advertising to their children. Although little is known regarding how parents' attitudes toward advertising to children is associated with their mediation practice, it is expected that those with stronger negative attitudes toward advertising to children will be more likely to talk to their children about advertising in order to minimize the potentially negative influence of advertising. This prediction is further corroborated by the literature of the Theory of Reasoned Action (Fishbein and Ajzen, 2011), which suggest that one's attitude is an important determinant of his/her behavior:

H3: Parents' negative attitudes toward advertising targeted to children through each type of media (television, computers, and smartphones) will be positively associated with their active mediation of advertising through each medium.

Another understudied but potentially important perceptual factor to examine in relation to active mediation is how parents view themselves as socialization agents (Shin, 2015). Research on parental self-efficacy suggests that the extent to which parents feel competent in their parental roles influences their parenting practices (Glatz and Buchanan, 2015). Parental self-efficacy refers to a set of beliefs or expectations that parents hold regarding their ability to parent successfully (Jones and Prinz, 2005); it constitutes one domain of personal self-efficacy, which is defined as the perception that one holds about his or her own capability to exercise control over behavioral performances (Bandura, 1997). Parents with higher parental self-efficacy are more likely than those with lower parental self-efficacy to demonstrate effective parenting even when 
facing challenging parenting situations (Jones and Prinz, 2005). Parental self-efficacy is also associated with greater use of positive parenting practices (i.e. cultivating children's skills and interests while preventing negative adjustments) (Glatz and Buchanan, 2015; Jones and Prinz, 2005). The belief that one can influence his/her child in a positive way also leads the parent to be more involved in the child's education (Glatz and Buchanan, 2015). Considering that parental self-efficacy is likely to be expressed through various parenting practices (Jones and Prinz, 2005), parental mediation is likely to be one of the many behaviors influenced by parental selfefficacy. Specifically, it is expected that parents with stronger parental self-efficacy would be more likely to engage in higher levels of active mediation, especially in view of the fact that parental self-efficacy is positively associated with promotive parenting practices and that active mediation is considered a type of promotive parenting practice involving parent-child discussion on media and media messages (Clark, 2011). Thus, it is expected that parental self-efficacy will be positively associated with active mediation of children's use of media and consumption of media messages, including advertising:

H4: Parental self-efficacy will be positively associated with their active mediation of advertising through each type of media.

\section{Method}

\section{Sample and Procedure}

A third-party research company, Qualtrics, was engaged to conduct an online survey for this study. The sample was drawn from Qualtrics' panel with the criterion that each participant be a parent residing in Singapore. Those who accessed the survey site were required to respond to two screening questions before participating in the questionnaire: (1) whether the participant is a parent with at least one child aged 10 to 17 years, and (2) whether his/her child watches 
television, uses a computer with Internet access, and uses a smartphone. The definition of smartphone - a mobile phone on which one's child can use mobile applications (apps) or conduct online searches_—was provided throughout the questionnaire, including in the screening portion. Seven hundred and three participants accessed the questionnaire, and $42 \%(N=306)$ of whom responded "yes" to both questions and completed the survey.

The qualified participants were randomly assigned to one of two conditions. Half of them were asked to think about their youngest child, and the other half was asked to think about their oldest child when answering the questions about their children, if they had more than one child aged 10-17. The median amount of time that the respondents spent answering the questionnaire was 14 minutes.

This study focuses on parents of children in Singapore. Singapore is a developed country with high television (100\%), Internet (82.5\%), and mobile phone (148.4\%) penetration rates (CASBAA, n.d.; Infocomm Development Authority of Singapore, 2016; Internet Live Stats, 2016). Almost all households with school-aged children (98\%) have Internet access (Infocomm Development Authority of Singapore, 2014), and $83 \%$ of parents allow their children to use mobile devices at home (theAsianparent Insights, 2014). More importantly, as in many other countries, children in Singapore are increasingly targeted by various forms of advertising through multiple media, potentially exposing them to abundant advertising messages (Media Literacy Council, n.d.).

The pool of respondents was evenly mixed in gender, with $47 \%$ male and $53 \%$ female, and was predominantly of Chinese ethnicity (87\%). Most responding parents were aged above 41 years $(72 \%)$ and held at least a tertiary diploma or bachelor's degree $(59 \%)$. The median

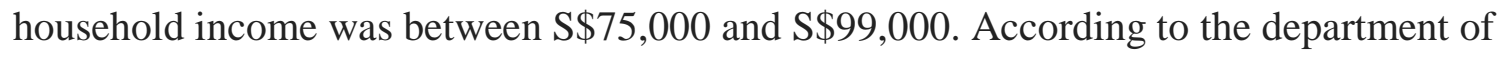


Statistics Singapore (2016), 74.1\% of the population is of Chinese ethnicity, $39 \%$ holds at least a tertiary diploma or bachelor's degree, and the median household income is approximately $\mathbf{S} \$ 99,000$. Overall, then, the sample of parents in this study is similar to the Singaporean population in terms of gender and household income but includes respondents with a higher average level of education than the general population and slightly over-represents Chinese ethnicity.

\section{Measures}

Active mediation of adverting was measured by asking respondents to rate how often they talk to their child about proper ways of understanding advertising on television, Internet advertising, and mobile advertising. The items were adapted from Buijzen's parental advertising mediation scale (2009) and measured on a 5-point scale $(1=$ never; $5=$ all the time $)$. Definitions of Internet advertising (any advertising and marketing messages promoting products or services that you may come across when you surf the Internet using a computer) and mobile advertising (any advertising and marketing messages promoting products or services that you may come across when you use a smartphone) were provided to ensure that participants had a common understanding of those concepts.

Active mediation of media was measured by asking respondents to rate how often they talk about proper ways of understanding television, computers with Internet access, and smartphones, on a 5 -point scale $(1=$ never; $5=$ all the time $)$. The items were adapted from prior

research on active parental mediation of children's media use (Livingstone et al., 2011; Shin and Kang, 2016).

Parents' concern about the effects of media on their children was assessed by asking respondents to indicate the extent to which they are concerned about various aspects of their 
child's viewing/using of television, computers with Internet access, and smartphones. Items were adapted from prior research on parental perceptions of media influence on children (Lee and Chae, 2012; Nikken et al., 2007; Ofcom, 2014).

Parents' attitude toward advertising to children was assessed by asking parents to rate the degree to which they express reservation about advertising aimed at children appearing on television, computers with Internet access, and smartphones. The items were adapted from Carlson and Grossbart (1988) and measured on a 5-point scale ( 1 = strongly disagree; $5=$ strongly agree). Higher scores indicate more negative attitudes toward advertising to children.

Parental self-efficacy was measured using an adapted parental self-efficacy scale from the Parenting Sense of Competence (PSOC) inventory (Johnston and Mash, 1989).

The questionnaire also collected demographic information of the respondents and their child (age, gender, household income, ethnicity, and education level). Table 1 presents the measurement items and descriptive statics.

\section{$<$ Table 1>}

\section{Results}

RQ1 asked to what extent parents engage in active mediation to influence their children's understanding of advertising on television, computers with Internet access, and smartphones. Table 1 shows that the level of active mediation the participants reported engaging in is similar across different media, in each case around the mid-point $(M=3.32$ for television advertising, $M$ $=3.33$ for Internet advertising, and $M=3.29$ for mobile advertising).

RQ2 asked whether there are positive associations between parental mediation of advertising and parental mediation of media. As the zero-order correlations between parental mediation variables show (Table 2), active mediation of television, Internet, and mobile 
advertising is significantly and positively associated with active mediation of television ( $r$ $=.467, p<.001)$, computers $(r=.643, p<.001)$ and smartphones $(r=.320, p<.001)$, respectively.

\section{< Table 2 >}

With regard to the antecedents of active mediation of advertising, this study predicted that active mediation of advertising would be negatively associated with children's age (H1) and positively associated with parents' concern about each medium's influence on their children (H2), parents' negative attitudes toward advertising targeting children in each medium (H3), and parental self-efficacy $(\mathbf{H 4})$. To test these hypotheses, a series of multiple regression analyses were performed, using the three active mediation of advertising variables as dependent variables. Table 3 presents the results.

\section{$<$ Table 3>}

Children's age emerged as a significant and negative predictor of parental mediation of Internet advertising $(\beta=-.103, p<.05)$ and mobile advertising $(\beta=-.106, p<.05)$. However, the associations were rather weak. In addition, children's age was not significantly associated with active mediation of television advertising. Thus, H1 was partially and weakly supported.

Parents' concern about their child's use of television, computers, and smartphones was positively associated with active mediation of television advertising $(\beta=.222, p<.001)$, Internet advertising on computers $(\beta=.343, p<.001)$, and mobile advertising on smartphones $(\beta=.276$, $p<.001)$, respectively. Thus, $\mathbf{H 2}$ was confirmed.

With regard to parents' negative attitudes toward advertising to children in each medium, attitudes toward television advertising and Internet advertising were significantly and positively associated with active mediation of television advertising $(\beta=.259, p<.001)$ and Internet 
advertising $(\beta=.147, p<.01)$, respectively. However, attitude toward mobile advertising targeted to children on smartphones did not emerge as a significant predictor of active mediation of mobile advertising. Thus, $\mathbf{H 3}$ was supported for television and Internet advertising only.

Lastly, parental self-efficacy was found to be a significant and positive predictor of all types of active mediation $(\beta=.289, p<.001$ for television advertising; $\beta=.268, p<.001$ for Internet advertising; $\beta=.337, p<.001$ for mobile advertising), supporting $\mathbf{H 4}$.

To further examine the nature of active mediation of advertising in comparison to active mediation of media use more generally, a series of additional regression analyses were conducted. For these post-hoc analyses, the three active mediation of media variables were entered as dependent variables and the same predictors tested in earlier regression analyses were entered as independent variables. Table 4 displays the results.

\section{$<$ Table 4>}

Children's age was significantly and negatively associated with all three media mediation variables, and the association between children's age and parental mediation of media appeared to be stronger than the association between children's age and parental mediation of advertising. Consistent with what the regression analyses on advertising mediation revealed, parents' concern about children's use of media was significantly and positively associated with their mediation of corresponding media. The same pattern was found for parental self-efficacy: The more parents felt competent about their ability to parent successfully, the greater active mediation they engaged in to influence their children's media use. However, parents' negative attitude toward advertising targeting children was not significantly associated with active mediation of media. 


\section{Discussion}

Today's children are multitaskers, often using multiple media concurrently (Common Sense Media, 2015). This increases their chances of exposing themselves to various types of advertising across different media platforms. However, not all advertising messages are viewed as beneficial for children, and some of the advertising practices targeting children have raised concerns among parents (Wilcox et al., 2004). Research on parental mediation suggests that parents can influence the way children understand media messages (Warren, 2001) and that communication-based active mediation is more effective than other forms of parental mediation to modify children's media-related attitudes and behavior (Lwin et al., 2008; Yoon, 2008). However, little research has been done to examine how parents engage in active mediation of advertising across different media. This study addresses that gap in the literature by investigating the extent to which parents engage in active mediation to influence children's exposure to and understanding of advertising in three different media (television, computers with Internet access, and smartphones), and the factors associated with parental mediation of advertising.

Parents in this study engaged in active mediation of advertising at a moderate level (measuring on average close to the mid-point of 3, which indicates "sometimes"), and the degree to which they implemented active mediation of advertising was similar across different media. The three advertising mediation variables were significantly and positively correlated with one another. In addition, parental mediation of advertising in each medium (television advertising, Internet advertising on computers and mobile advertising on smartphones) was positively and strongly associated with parental mediation of each corresponding medium. From these findings, we can infer that active mediation is a general and pervasive socialization tendency displayed among parents across a range of media contexts. Parents who talk about advertising on television 
also frequently talk about advertising in new media. In addition, those who actively engage in media education in general are also more likely to talk about the pros and cons of advertising to their children, potentially enhancing children's understanding of advertising and developing persuasion knowledge (Friestad and Wright, 1994). This study encourages future research to examine a wider range of mediation strategies (e.g. restrictive mediation, co-use, and monitoring) in various advertising and media contexts to gain a deeper understanding of parents' tendencies in parental mediation that might affect children's understanding of advertising in general and of specific forms of advertisements in particular.

This study also examined how different child and parent factors were associated with active mediation of advertising and of media use more generally. Children's age was significantly and negatively associated with active mediation of all three types of media, corroborating previous studies on parental mediation of media (Nathanson, 2001; Warren et al., 2002; Shin and Lwin, 2017). However, child's age was rather weakly or not significantly associated with parental mediation of advertising. Overall, these findings suggest that parental mediation of advertising is more a function of parental factors (e.g. parents' concerns about media influence on children, parents' attitudes toward advertising, and parental self-efficacy) than of their children's age.

Specifically, the results show significant and positive associations between parents' concerns about media influence on their children and parental mediation of advertising. This finding is in line with prior studies demonstrating that parents presuming negative media influence on their children are more likely to engage in parental mediation. This tendency can be explained by the influence of the presumed influence model (Gunther and Storey, 2003), which suggests that our attitudes and behaviors directed to others are affected by our perceptions of 
media influence on the others. Future research could investigate how parents' presumed influence of media on their children is shaped by various factors, such as parents' personality characteristics, prior media experiences, as well as their children's media usage patterns.

Parental self-efficacy was also significantly and positively associated with active mediation of all three types of advertising. According to Bandura and Schuk (1981), high selfefficacy leads individuals to put in greater effort to achieve goals and to effectively carry on with behaviors even in the face of challenges. Research on parental self-efficacy suggests that parents have different levels of self-efficacy regarding their parenting ability and those with high parental self-efficacy are more likely to believe that they can influence their children's behavior in a positive way, which leads them to more actively engage in child rearing and education (Glatz and Buchanan, 2015; Jones and Prinz, 2005). Given that active mediation involving parent-child conversation and discussion is a more hands-on, promotive form of mediation as compared to control-based restrictive mediation or simple parent-child media co-use, the positive association between parental self-efficacy and active mediation of advertising was expected. Future research could examine how parental self-efficacy is associated with other forms of parental mediation (e.g., restrictive mediation) and whether the relationships between parental self-efficacy and parental mediation are affected by other forms of self-efficacy such as perceived media skills.

As expected, parents' attitudes toward television and Internet advertising targeted to children were found to be significantly associated with their engagement in active mediation of television and Internet advertising, respectively. However, there was no significant association between parents' attitudes toward mobile advertising targeted to children and their engagement in active mediation of mobile advertising. Descriptive analyses (Table 1) show that parents have 
more negative attitudes toward television $(M=3.26, S D=.63)$ and Internet advertising $(M=$ 3.37, $S D=.58)$ than mobile advertising $(M=1.91, S D=.91)$. The low level of attitudes toward mobile advertising might have reduced the chances of finding a significant relationship between this variable and active mediation. The seemingly low level of attitudes toward mobile advertising might be attributable to the fact that mobile advertising is relatively new as compared to television and Internet advertising, and thus, parents have yet to shape their attitudes toward mobile advertising directed to children. The difference in findings in parental mediation of mobile advertising versus other forms of advertising calls for further empirical research. For example, one could examine whether parents are aware of specific forms of mobile advertising practices targeting children and whether this awareness influences their attitudes toward mobile advertising in general.

Finally, as discussed earlier, active mediation of advertising was found to be significantly correlated with parental mediation of media and that both types of mediation were positively associated with parents' concerns about media influence on children and parental self-efficacy. However, parents' attitude toward advertising targeting children was associated with active mediation of advertising, but not with active mediation of media usage. In addition, children's age was more closely associated with active mediation of media rather than active mediation of advertising. This implies that although parental mediation of advertising is closely related to parental mediation of media, the two remain distinct in that one focuses on a specific type of communication while the other concerns media in general. Future research is encouraged to identify factors that may be specifically associated with parental mediation of advertising (e.g. parents' advertising skepticism, parents' knowledge and understanding of different forms of 
advertising strategies and tactics in different media) to enhance our understanding of how parental mediation of advertising works.

This study has limitations. First, it was conducted in a single country. Although Singapore constitutes an appropriate research site, the findings may be most applicable to countries with high levels of screen media penetration. In addition, the country places a great emphasis on collectivism and children's deference to parents (Stright and Yeo, 2004). As national culture and parenting styles can influence parental practices, caution should be exercised when projecting the findings of this study to a culturally different research context. Second, although this study tried to investigate a wide range of parent factors, future studies could examine a wider range of child and parent factors as potential antecedents of parental mediation of advertising, including children's media activities, parents' media literacy and their knowledge of the persuasive intentions of various forms of advertising. Third, while this study examined antecedents of active mediation of advertising, future research is encouraged to examine the consequences of parental mediation of advertising, including children's perceptions and knowledge of advertising and their behavioral responses to advertising. Lastly, this study examined television advertising, Internet advertising, and mobile advertising in general despite the fact that there are various forms of advertising under each broad category. Future research should consider examining parental mediation of specific forms of advertising such as advergames, mobile apps promoting brands, and product placements in television programs.

Despite the limitations, this study adds novel insights to the literature on consumer socialization by exploring how parents - the primary socialization agents in children's acquisition and development of consumption-related attitudes and skills (John, 1999)-help their children understand advertising across different media. While parents are expected to take an 
active role in protecting their children from any harmful media influence, including "unintended effects of advertising," little is known regarding parental involvement in advertising mediation and the factors affecting their mediation behavior. The findings from this study suggest that parental mediation of advertising is a function of various parental factors and is closely associated with parents' tendency to educate children on media in general. Media educators and policy makers are encouraged to consider parental factors in their development of educational programs or guidelines for parents to encourage them to take a more active role in educating children on advertising. Media literacy programs that encourage parents to talk about various media issues with their children will also help parents to cope with the challenges posed by new forms of advertising.

For advertising practitioners, this study demonstrates that parents in Singapore have more negative attitudes toward television and Internet advertising than mobile advertising, and such negative attitudes could lead to more active engagement in parental mediation. Given that parents are important consumer socialization agents and gatekeepers of children's media use and that their engagement in active mediation could shape children's attitude and skepticism toward advertising, it is important for advertisers targeting children to develop a deeper understanding of how parents feel about different forms of advertising and factors associated with parents' attitude toward advertising.

\section{Conclusion}

Given the fact that children are likely to be exposed to various types of advertising through multiple media and that parents can have an important influence on children's viewing and understanding of advertising messages, this study focuses on communication-based active mediation of advertising across three different media: television, computers with Internet access, 
and smartphones. This study demonstrates that active mediation is a pervasive parental socialization tendency exhibited across different media contexts. It also shows that active mediation of advertising is a function of parents' perceptions of media effects, attitude towards advertising targeted to children, and self-efficacy, rather than the age of children. These findings have substantial implications for advertisers, media educators, and policy makers, highlighting the importance of an in-depth understanding of parents as primary socialization agents. However, this study is limited in that it is based on a survey conducted in a single country and did not examine the consequences of active mediation of advertising. Future research that considers cross-cultural perspectives and investigates the potential outcomes of active mediation would be especially beneficial. The author also encourages future research to examine a wider range of child and parent factors as potential determinants of parental mediation of various forms of advertising. 


\section{References}

theAsianparent Insights (2014), "Mobile device usage among young kids: a South Asia study", available at: https://s3-ap-southeast-1.amazonaws.com/tap-sgmedia/theAsianparent+Insights+Device+Usage + A + Southeast + Asia + Study + November +20 14.pdf (accessed 9 May 2015).

Austin, E.W., Bolls, P., Fujioka, Y. and Engelbertson, J. (1999), "How and why parents take on the tube", Journal of Broadcasting \& Electronic Media, Vol. 43 No. 2, pp. 175-92

Austin, E.W. and Pinkleton, B.E. (2001), "The role of parental mediation in the political socialization process", Journal of Broadcasting \& Electronic Media, Vol. 45 No. 2, pp. $221-40$.

Austin, M.J. and Reed, M.L. (1999), “Targeting children online: Internet advertising ethics issues", Journal of Consumer Marketing, Vol. 16 No. 6, pp. 590-602.

Bandura, A. (1997), Self-efficacy: The Exercise of Self-control. New York: Freeman.

Bandura, A. and Schunk, D.H. (1981), "Cultivating competence, self-efficacy, and intrinsic interest through proximal self-motivation", Journal of Personality and Social Psychology, Vol. 41, pp. 586-96.

Bijmold, T.H.A., Claassen, W. and Brus, B. (1998), “Children's understanding of TV advertising: effects of age, gender, and parental influence", Journal of Consumer Policy, Vol. 21 No. 2, pp. 171-94.

Buijzen, M. (2009), "The effectiveness of parental communication in modifying the relation between food advertising and children's consumption behavior", British Journal of Developmental Psychology, Vol. 27, pp. 105-21. 
Buijzen, M. and Valkenburg, P.M. (2003), “The unintended effects of television advertising: a parent-child survey", Communication Research, Vol. 30 No. 5, pp. 483-503.

Buijzen, M. and Valkenburg, P.M. (2005), "Parental mediation of undesired advertising effects", Journal of Broadcasting \& Electronic Media, Vol. 49 No. 2, pp. 153-65.

Carlson, L. and Grossbart, S (1988), "Parental style and consumer socialization of children”, Journal of Consumer Research, Vol. 15 No. 1, pp. 77-94.

CASBAA. (n.d.), "Singapore”, available at: http://www.casbaa.com/advertising/countries/singapore (accessed 15 September 2016).

Clark, L.S. (2011), "Parental mediation theory for the digital age", Communication Theory, Vol. 21 No. 4, pp. 323-43.

Common Sense Media (2013), "Zero to eight: children's media use in America 2013”, available at: https://www.commonsensemedia.org/ (accessed 15 September 2016).

Common Sense Media (2015), “The Common Sense Census: media use by tweens and teens”, available at: https://www.commonsensemedia.org/ (accessed 15 September 2016).

Department of Statistics Singapore. (2016), "Statistics of Singapore: census of population", available at: http://www.singstat.gov.sg/docs/default-source/default-documentlibrary/publications/publications_and_papers/cop2010/census_2010_release1/cop2010sr1. pdf (accessed 18 August 2016)/

Dens, N., De Pelsmacker, P. and Eagle, L. (2007), "Parental attitudes toward advertising to children and restrictive mediation of children's television viewing in Belgium", Young Consumers, Vol. 8 No. 1, 7-18.

Federal Trade Commission (2013), "Mobile privacy disclosures: Building trust through transparency", available at: http://www.ftc.gov/reports/mobile-privacy-disclosures-buildingtrust-through-transparency-federal-trade-commission (accessed 20 November, 2016). 
Fishbein, M. and Ajzen, I. (2011), Predicting and Changing Behavior: The Reasoned Action Approach, New York, NY: Taylor \& Francis.

Friestad, M. and Wright, P. (1994), “The persuasion knowledge model: how people cope with persuasion attempts", Journal of Consumer Research, Vol. 21 No. 1, 1-31.

Fujioka, Y. and Austin, E.W. (2003), “The implications of vantage point in parental mediation of television and child's attitudes toward drinking alcohol", Journal of Broadcasting \& Electronic Media, Vol. 47 No. 3, pp. 418-34.

Glatz, T. and Buchanan, C.M. (2015), "Over-time associations among parental self-efficacy, promotive parenting practices, and adolescents externalizing behaviors”, Journal of Family Psychology, Vol. 29 No. 3, pp. 427-37.

Hoffner, C. and Buchanan, M. (2002), "Parents' responses to television violence: the thirdperson perception, parental mediation and support for censorship", Media Psychology, Vol. 4, No. 3, pp. 231-52.

Infocomm Development Authority of Singapore (2014), “Annual survey on infocomm usage in households and by individuals for 2014”, available at: https://www.imda.gov.sg/ (accessed 1 October 2016).

Infocomm Development Authority of Singapore (2016), “Telecommunications”, available at: https://www.ida.gov.sg/Tech-Scene-News/Facts-and-Figures/Telecommunications (accessed 20 September 2016).

Internet Live States (n.d.), "Singapore internet users." available at: http://www.internetlivestats.com/internet-users/singapore/ (accessed 2 October 2016). John, D.R. (1999), “Consumer socialization of children: a retrospective look at twenty-five years of research”, Journal of Consumer Research, Vol. 26 No. 3, pp. 183-213. 
Johnston, C. and Mesh, E.J. (1989), “A measure of parenting satisfaction and efficacy”, Journal of Clinical Child Psychology, Vol 18, pp. 167-75.

Jones, T.L. and Prinz, R.K. (2005), "Potential roles of parental self-efficacy in parent and child adjustment: a review”, Clinical Psychology Review, Vol. 25, pp. 341-63.

Kowalczyk, C.M. and Royne, M.B. (2016), "Exploring the influence of mothers' attitudes toward advertising on children's consumption of screen media", International Journal of Consumer Studies, Vol. 40 No. 5, pp. 610-17.

Laczniak, R.N. and Carlson, L. (2012), “A theory of advertising to children”, in Thorson, E. and Rodgers, S.L. (Ed.), Advertising Theory, New York: Routledge, pp. 135-148

Lee, S.-J. and Chae, Y.-G. (2012), "Balancing participation and risks in children's Internet use: the role of Internet literacy and parental mediation", Cyberpsychology, Behavior, and Social Networking, Vol. 15 No. 5, pp. 257-62.

Livingstone, S., Haddon, L., Gorzig, A. and Olafsson, K. (2011), “EU Kids Online (September 2011)", available at: http://www.lse.ac.uk/media\%401se/research/EUKidsOnline/EU\%20Kids\%20II\%20(200911)/EUKidsOnlineIIReports/Final\%20report.pdf (accessed 6 June 2014).

Lwin, M.O., Stanaland, A.J.S. and Miyazaki, A.D. (2008), "Protecting children's privacy online: how parental mediation strategies affect website safeguard effectiveness", Journal of Retailing, Vol. 84 No. 4, pp. 205-17.

McAfee (2012), “70\% of teens hide their online behavior from their parents, McAfee reveals what U.S. teens are really doing online, and how little their parents actually know", available at: http://www.mcafee.com/sg/about/news/2012/q2/20120625-01.aspx (accessed 10 May 2014). 
Media Literacy Council (n.d.), "Media issues: marketing messages”, available at: http://www.medialiteracycouncil.sg/media-issues/Pages/marketing-messages.aspx (accessed 28 September 2016).

Moore, E.S. (2006), “It's child's play: advergaming and the online marketing of food to children", available at: https://kaiserfamilyfoundation.files.wordpress.com/2013/01/7536.pdf (accessed 29 September 2016).

Moore, E.S. and Lutz, R.J. (2000), “Children, advertising, and product experiences: A multimethod inquiry", Journal of Consumer Research, Vol. 27, pp. 31-48.

Nathanson, A.I. (2001), "Parent and child perspectives on the presence and meaning of parental television mediation”, Journal of Broadcasting \& Electronic Media, Vol. 45 No. 2, 20120.

Neeley, S. (2007), “Internet advertising and children”, in Schumann, D.W. and Esther, T. (Ed.), Internet Advertising: Theory and Research, Mahwah: LEA, pp. 343-62.

Nikken, P. and Jansz, J. (2006), "Parental mediation of children's videogame playing: a comparison of the reports by parents and children," Learning, Media \& Technology, Vol. 31 No. 2, pp. 181-202.

Nikken, P., Jansz, J. and Schouwstra, S. (2007), "Parents' interest in videogame ratings and content descriptors in relation to game mediation", European Journal of Communication, Vol. 22 No. 3, pp. 315-36.

Ofcom (2014), “The communications market report”, available at: http://stakeholders.ofcom.org.uk/binaries/research/cmr/cmr14/2014_UK_CMR.pdf (accessed 19 March 2015). 
Opgenhaffen, M., Vandenbosch, L., Eggermont, S. and Frison, E. (2012), "Parental mediation of television viewing in the context of changing parent-child relationships in Belgium: a latent growth curve analysis in early and middle adolescence”, Journal of Children and Media, Vol. 6 No. 4, pp. 469-84.

Schor, J. (2004), Born to Buy: The Commercialized Child and the New Consumer Culture: New York: Scribner.

Shin, W. (2015), "Parental socialization of children's Internet use: a qualitative approach”, New Media \& Society, Vol. 17 No. 5, pp. 649-65.

Shin, W. and Kang, H.J. (2016), “Adolescents' privacy concerns and information disclosure online: the role of parents and the Internet", Computers in Human Behavior, Vol. 54, pp. 114-23.

Shin, W. and Lwin, M.O. (2017), "How does "talking about the Internet with others" affect teenagers' experience of online risks? the role of active mediation by parents, peers, and school teachers", New Media \& Society. Vol. 19 No. 7, pp. 1109-1126.

Stright, A.D. and Yeo, K.L. (2014)", Maternal parenting styles, school involvement, and children's school achievement and conduct in Singapore”, Journal of Educational Psychology, Vol. 106 No. 1, pp. 301-14.

Valkenburg, P.M., Piotrowski, J.T., Hermanns, J. and de Leeuw, R. (2013), “Developing and validating the perceived parental media mediation scale: a self-determination perspective", Human Communication Research, Vol. 39 No. 4, pp. 445-69.

Vanwesenbeeck, I., Walrave, M. and Ponnet, K. (2016), "Young adolescents and advertising on social network games: a structural equation model of perceived parental media mediation, 
advertising literacy, and behavioral intention", Journal of Advertising, Vol. 45 No. 2, pp. 183-97.

Wakefield, J. (2015), "Children spend six hours or more a day on screens", BBC News, available at: http://www.bbc.com/news/technology-32067158 (accessed15 September 2016).

Warren, R. (2001), “In words and deeds: parental involvement and mediation of children's television viewing", Journal of Family Communication, Vol. 1 No. 4, pp. 211-31.

Wilcox, B.L., Kunkel, D., Cantor, J., Dowrick, P., Linn, S.and Palmer, E. (2004), Report of the APA Task Force on Advertising and Children. American Psychological Association.

Youn, S. (2008), "Parental influence and teens' attitude toward online privacy protection", Journal of Consumer Affairs, Vol. 42 No. 3, pp. 362-88. 
Table 1. Measurement Items and Statistics

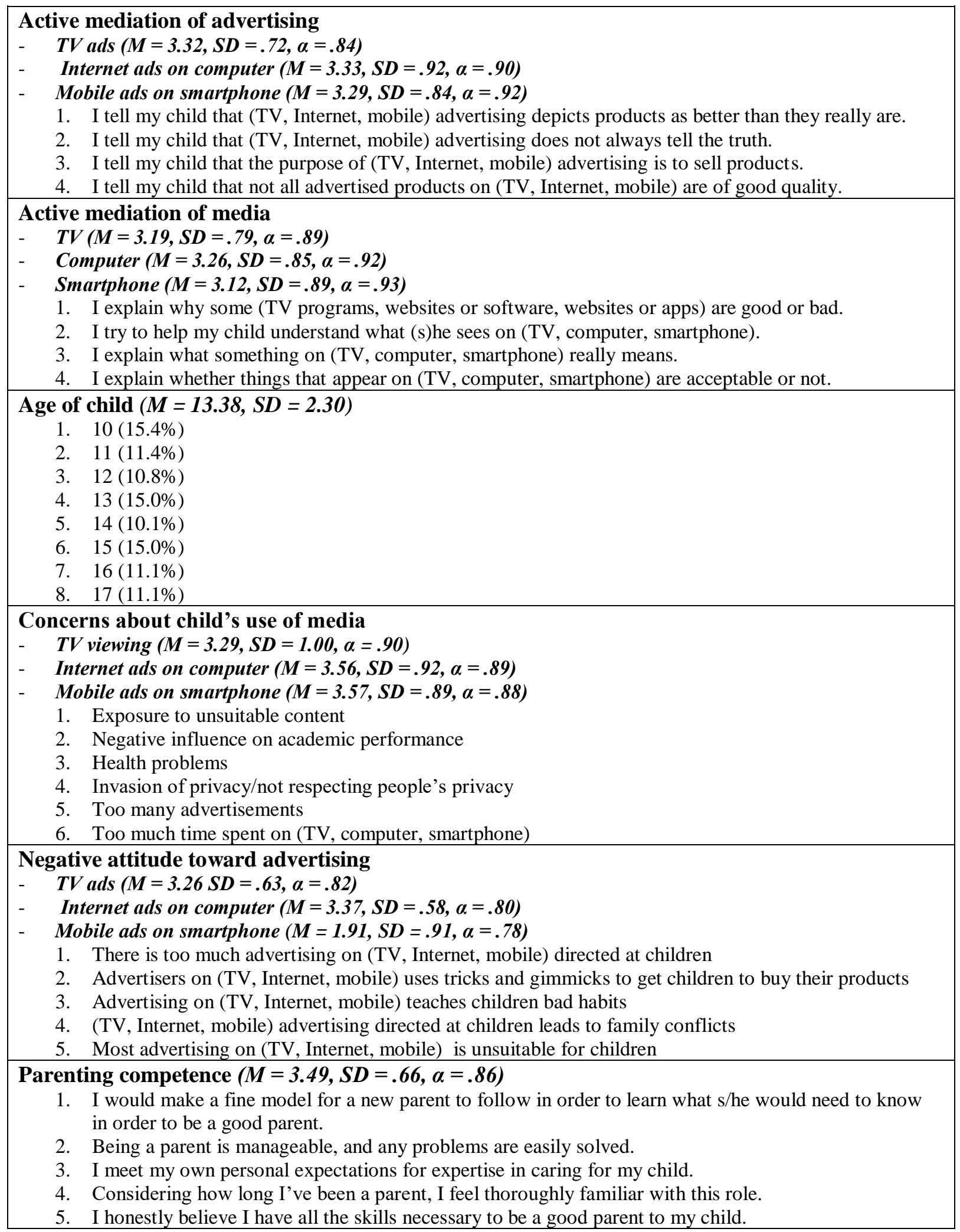


Table 2. Zero-Order Correlations between Active Mediation Variables $(r)$

\begin{tabular}{llcccccc}
\hline & & \multicolumn{2}{c}{ Television } & \multicolumn{2}{c}{ Computer } & \multicolumn{2}{c}{ Smartphone } \\
& & Ad & Medium & Ad & Medium & Ad & Medium \\
\hline \multirow{2}{*}{ Television } & Ad & 1 & & & & & \\
& Medium &. $\mathbf{4 6 7 * * *}$ & 1 & & & & \\
\multirow{2}{*}{ Computer } & Ad & $.703 * * *$ & $.497 * * *$ & 1 & & & \\
& Medium & $.530^{* * *}$ & $.707 * * *$ &. $\mathbf{6 4 3} * * *$ & 1 & & \\
\multirow{2}{*}{ Smartphone } & Ad & $.726 * * *$ & $.452^{* * *}$ & $.781 * * *$ & $.601 * * *$ & 1 & \\
& Medium & $.335^{* * *}$ & $.346^{* * *}$ & $.433^{* * *}$ & $.437 * * *$ & $\mathbf{. 3 2 0} * * *$ & 1 \\
\hline
\end{tabular}

$*<.05, * * p<.01, * * * p<.001$. 
Table 3. Multiple Regressions for Predicting Active Mediation of Advertising ( $\beta$ )

\begin{tabular}{|c|c|c|c|}
\hline & $\begin{array}{l}\text { Television } \\
\text { advertising }\end{array}$ & $\begin{array}{c}\text { Internet } \\
\text { advertising } \\
\text { (on computer) }\end{array}$ & $\begin{array}{c}\text { Mobile } \\
\text { advertising } \\
\text { (on smartphone) }\end{array}$ \\
\hline Age of child & -.028 & $-.103 *$ & $-.106^{*}$ \\
\hline $\begin{array}{l}\text { Parent's concern about the child's use of } \\
\text { the medium }+\end{array}$ & $.222 * * *$ & $.343 * * *$ & $.276 * * *$ \\
\hline $\begin{array}{l}\text { Parent's negative attitude toward ads in } \\
\text { the medium }+\end{array}$ & $.259 * * *$ & $.147 * *$ & .009 \\
\hline \multirow[t]{2}{*}{ Parental self-efficacy } & $.289 * * *$ & $.268 * * *$ & $.337 * * *$ \\
\hline & $\begin{array}{c}\text { Adj } R^{2}=.253 \\
F=26.869 \\
p<.001\end{array}$ & $\begin{array}{c}\operatorname{Adj} R^{2}=.275 \\
F=29.876 \\
p<.001\end{array}$ & $\begin{array}{c}\operatorname{Adj} R^{2}=.210 \\
F=20.911 \\
p<.001\end{array}$ \\
\hline
\end{tabular}

$*<.05, * * p<.01, * * * p<.001$.

+ Each corresponding media for each of DVs. 
Table 4. Multiple Regressions for Predicting Active Mediation of Media ( $\beta$ )

\begin{tabular}{|c|c|c|c|}
\hline & Television & Computer & Smartphone \\
\hline Age of child & $-.158 * *$ & $-.152 * *$ & $-.235 * * *$ \\
\hline $\begin{array}{l}\text { Parent's concern about the child's use of } \\
\text { the medium+ }\end{array}$ & $.431^{* * *}$ & $.401 * * *$ & $.377 * * *$ \\
\hline $\begin{array}{l}\text { Parent's negative attitude toward ads in the } \\
\text { medium+ }\end{array}$ & -.056 & .093 & .052 \\
\hline \multirow{2}{*}{ Parental self-efficacy } & $.236^{* * * *}$ & $.309 * * *$ & $.224 * * *$ \\
\hline & $\begin{array}{c}\text { Adj } R^{2}=.290, \\
F=30.748, \\
p<.001\end{array}$ & $\begin{array}{c}\text { Adj } R^{2}=.342, \\
F=40.576 \\
p<.001\end{array}$ & $\begin{array}{c}\text { Adj } R^{2}=.268, \\
F=28.885, \\
p<.001\end{array}$ \\
\hline
\end{tabular}

+ Each corresponding media for each of DVs. 